\title{
OBITUARY
}

\section{In memoriam: Warren M. Zapol}

\author{
Lorenzo Berra ${ }^{1 *} \mathbb{D}$, Konrad J. Falke ${ }^{2}$, Roland C. E. Francis ${ }^{2}$, Jesse D. Roberts ${ }^{3}$ and Jean-Daniel Chiche ${ }^{4}$
}

C 2022 Springer-Verlag GmbH Germany, part of Springer Nature

Warren M. Zapol, a giant in intensive care medicine and respiratory sciences, passed away on December 14, 2021 (Fig. 1). Zapol spent 52 years at the Massachusetts General Hospital (MGH) advancing biomedical sciences and mentoring generations of physician-scientists.

Warren Myron Zapol was born on March 16, 1942, in Brooklyn, NY. He was adopted at birth by Florence Zapol, a schoolteacher, and Bernard ("Ben") Zapol, a businessman. Warren's parents provided a fertile learning environment to engage the boundless curiosity of their child with violin lessons, building an amateur radio shack and tower, and allowing him to build small rockets. His passion for discovery and exploring the world grew exponentially while at Stuyvesant High School in Manhattan, and later at the Massachusetts Institute of Technology (MIT). Both institutions were a perfect match for Warren's voracious deep interests in science and technology.

Skipping his graduation ceremony from MIT in 1962, Warren led the "MIT South-West Asia Expedition". His team intended to drive a Land Rover from Hull, England to New Delhi, crossing Europe, Turkey, Iran, Afghanistan, and Pakistan. The trip was cut short after several weeks of Warren experiencing chills and fever, during which time he lost 20 pounds. After being admitted to the Holy Family Hospital in Rawalpindi, Pakistan, his life was saved by a Harvard-trained physician and Catholic sister who successfully treated him for malaria and amoebiasis. This experience cemented his desire to pursue a career in medicine.

After completing medical school at the University of Rochester, Warren spent his intern year (1966-1967) on the Harvard surgical service at Boston City Hospital. Afterwards, Warren joined the Public Health Service

\footnotetext{
*Correspondence: Iberra@mgh.harvard.edu

${ }^{1}$ Department of Anesthesia, Critical Care and Pain Medicine,

Massachusetts General Hospital and Harvard Medical School, 55 Fruit Street, Boston, MA, USA

Full author information is available at the end of the article
}

Program pursuing research at the US National Institutes of Health (NIH). He worked there until 1970 in the laboratory of Theodor "Ted" Kolobow. Under Ted's mentorship, his passion for physiology and critical care medicine grew as he witnessed the power of animal research to rigorously test important hypotheses. Using lambs, Warren tested Kolobow's novel silicone-membrane blood oxygenators as well as newly designed thin-walled, nonkinking, flexible spring wire-reinforced intravascular catheters. Warren loved to recount all the handmade devices he tested in the laboratory. They astounded the world with their first extracorporeal membrane oxygenator (ECMO) devices, demonstrating their utility to mediate gas exchange from the blood of awake and mechanically ventilated sheep for days. They also devised an "artificial placenta", which was a membrane oxygenator that could support prematurely delivered lamb fetuses even though the animals were submerged in an aquarium tank filled with synthetic amniotic fluid.

After leaving the NIH in 1970, Warren was determined to pursue a career in both clinical medicine and research. He chose to train in anesthesia at the MGH in Boston. At that time the MGH was established at the forefront of respiratory care. Henning Pontoppidan created the first respiratory intensive care unit in the United States (1961), which also included a blood-gas laboratory led by Myron B. Laver. Richard J. Kitz, then MGH Chair of Anesthesia, tailored a residency program for Warren, which granted him protected research time, assistance in obtaining NIH funding, and Department's resources to pursue his human ECMO studies. The nurturing, collaborative, and academic environment of the MGH provided Warren with the fertile ground to bloom as a scientist, clinician, teacher, leader and explorer.

Over the following decade, Warren worked tirelessly to develop ECMO as a life-saving therapy for acute respiratory distress syndrome (ARDS). He led the first multicenter randomized clinical trial ever conducted in critical care. The trial showed that ECMO could support

\section{Springer}




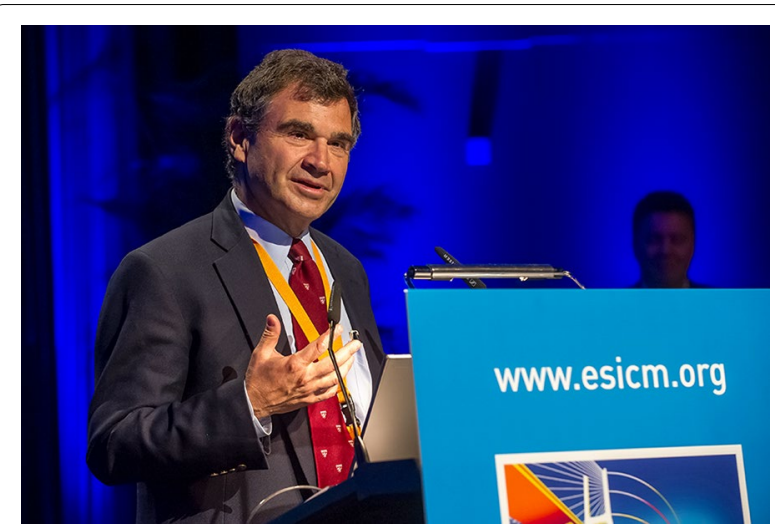

Fig. 1 Warren M. Zapol lecturing at the Annual Congress of the ESICM (Lisbon, Portugal. October 13-17, 2012)

respiratory gas exchange in critically ill patients with acute respiratory distress syndrome (ARDS), although it did not improve their long-term survival. He later opined that those disappointing results needed to be interpreted in light of the limitations at the time-ECMO technology had not yet evolved beyond the use of roller pumps and silicone membranes. Moreover, anticoagulation was used excessively, veno-arterial partial bypass access was suboptimal, and the knowledge of ARDS pathophysiology and ventilatory management were still very limited.

Warren approached the challenge of improving the treatment of ARDS, and many other medical conditions, by seeking the knowledge and support of experts from many different disciplines. He pursued collaborators across all disciplines (e.g., anesthesia, pediatrics, internal medicine, cardiology, intensive care, radiology, photomedicine, pathology and surgery), as well as laboratory scientists and engineers with advanced knowledge of molecular biology, chemistry, biochemistry, pathology, computer science and statistics. Warren was not satisfied with guesswork or superficial answers that were not supported by robust data; he truly wanted to know for certain. His intrepid pursuit of the body's response to hypoxia led him to study the adaptations of mammals to extreme conditions. Over nine austral summers in Antarctica, he studied the physiology of the Weddell seal. Sponsored by the National Science Foundation, Warren led teams of international collaborators. Their studies at McMurdo Station on the Ross Ice Shelf and Palmer Station on the Antarctic Peninsula involved the first remote computer microprocessor-enabled studies of freely diving Weddell seals in the wild. This novel technology provided new insights into the physiologic adaptations that evolution provided, allowing Weddell seal breath holds for up to 93 min during dives to depths of $500 \mathrm{~m}$ under the sea ice. He measured the physiological response of the seals during prolonged periods of hypoxia. To honor his adventurous spirit, groundbreaking findings, and contributions to polar exploration, the Advisory Committee on Antarctic Names (ACAN) named a glacier after Warren. The "Zapol Glacier" (78³5'S 8551 W) descends from Vinson Massif, the tallest peak in Antarctica.

By 1988, Warren became convinced that elevated pressure in the pulmonary arterial vasculature played an important role in morbidity and mortality in acute hypoxic respiratory failure as his previous work showed that intravenous nitroprusside and prostacyclins dilated the systemic vascular and pulmonary beds, sometimes causing severe hypotension. Around this time, the future Nobel laureates Robert Furchgott, Ferid Murad and Louis Ignarro discovered the role of nitric oxide (NO), a gaseous signaling molecule, in regulating the cardiovascular system. During a trip to California, Warren read a weather forecast in the Los Angeles Times noting the presence of nitrogen dioxide $\left(\mathrm{NO}_{2}\right)$ amongst the pollutants in the Los Angeles air. A spark lit up in his eyes. "I reasoned that ambient $\mathrm{NO}_{2}$, the product of atmospheric oxidation of NO, must have been produced first by internal combustion in cars and buses. Therefore, people had to be breathing NO in cities, in tunnels, and perhaps even more at rush hour". He called the United States Food and Drug Administration (FDA) and the Occupational Safety and Health Administration (OSHA) to learn the regulatory limits on $\mathrm{NO}$ and $\mathrm{NO}_{2}$ inhalation levels of this poisonous gas. Reasoning those low concentrations were acceptable to these regulatory agencies in workplaces, bus stations, he returned to the laboratory and with his team began testing the effects of low doses $(<80$ parts-per million) of inhaled NO. The first experiments were conducted in awake sheep with pulmonary hypertension induced by intravenous infusion of a thromboxane analogue. After only a few breaths of NO, they discovered that inhaled NO selectively decreased the pulmonary arterial pressures while leaving the systemic pressure unchanged. The team gasped as they witnessed the effects of this selective pulmonary vasodilator. Still to this day, no other drug exerts such a selective and powerful action on the pulmonary vasculature.

These amazing laboratory studies were rapidly translated to clinical trials at the MGH. With collaborators from pediatrics, cardiology, and other specialties, inhaled NO was tested in patients with a variety of pulmonary vascular diseases. The response in critically ill newborns with pulmonary hypertension and severe hypoxemia was most significant. In those patients, nearly $50 \%$ had a rapid increase in their blood oxygen levels while breathing low levels of NO gas. In 1999, the FDA approved the use of inhaled NO "for the treatment of term and near-term 
neonates with hypoxic respiratory failure". Inhaled NO is now an established, life-saving therapy that is used in critically ill babies worldwide. Companies that source this therapeutic gas estimate that over a million patients have been treated with inhaled NO.

Warren is also remembered for his executive skills and farsighted vision for the MGH Department of Anesthesia, Critical Care, and Pain Medicine. While Chair of that Department (1994-2008), he supported the establishment of the first laboratory dedicated entirely to pain medicine (the Neural Plasticity Lab), recruited and mentored a multitude of anesthesiologists who are now leading anesthesia departments around the globe, raised funds to endow three chairs in anesthesia at Harvard Medical School, and doubled the number of anesthesia staff as well as the number of anesthesia residents as the surgical volume increased.

On a broader scale, Warren served as a member of the Polar Research Board of the National Academy of Sciences. Presidents George W. Bush and Barack Obama appointed Warren as a member of the US Arctic Research Commission. There he supported studies on climate change, and spearheaded research aimed at increasing the health of indigenous Arctic people.

During his 52 years at MGH, the Zapol Laboratory produced 26 patents, hundreds of publications, and mentored a countless number of students, clinicians and researchers now scientists and independent investigators in basic research, translational medicine around the world and even in space at the International Space Station. Warren's work has been recognized by many awards and honors from scientific institutions worldwide, including Honorary membership of the European Society of Intensive Care Medicine. Warren met the challenges of his many roles with calmness, clarity, humanity, and optimism. He always offered a supportive word, a kind smile, and an extended hand for anyone in need.

While Warren was battling stage 4 lung cancer during the last 6 years of his life, he remained focused on his laboratory, fellows, and students. Together they continued to make scientific breakthroughs, unveiling the therapeutic effect of hypoxia in mitochondrial disease, understanding the biochemical and the protective role of inhaled NO during oxidative insults, discovering novel ways to treat carbon monoxide poisoning and describing the antimicrobial properties of inhaled NO. He also recognized that making inhaled $\mathrm{NO}$ available as a therapy in low-resource settings around the world and for patients outside of hospitals would require inventing an economical and light-weight device. He would often admonish: "don't forget the babies in Uganda." Warren's novel development of a method for generating NO from nitrogen in air via an electrical spark spawned the establishment of Third Pole Inc., a company that is developing NO-generating devices for use in patients worldwide.

For those of us who knew Warren, he will always be remembered as the positive kid from Brooklyn with a profound soul and inquisitive mind that conquered many hearts and saved many lives. He certainly has transformed our existence and he has shown us a clear path to follow in moments of success as well as in more difficult circumstances. We are eternally grateful to Nikki, his devoted spouse, to his children, David and Liza and their partners, and to their children, for the love and support they gave him, a solid foundation on which Warren was able to build his many contributions to humanity.

\section{Author details \\ ${ }^{1}$ Department of Anesthesia, Critical Care and Pain Medicine, Massachusetts General Hospital and Harvard Medical School, 55 Fruit Street, Boston, MA USA. ${ }^{2}$ Department of Anesthesiology and Intensive Care Medicine CCM/CVK, Charité-Universitätsmedizin Berlin, Augustenburger Platz 1, 13353 Berlin, Ger- many. ${ }^{3}$ Departments of Anesthesia, Critical Care and Pain Medicine, Pediatrics, and Medicine, Massachusetts General Hospital and Harvard Medical School, 55 Fruit Street, Boston, MA, USA. ${ }^{4}$ Department of Intensive Care Medicine, Centre Hospitalier Universitaire Vaudois, Lausanne, Switzerland.}

\section{Acknowledgements}

We thank Nikki Zapol, Liza Zapol, David Townsend, Diana Laird, David Zapol and Margaret Flynn for reviewing and providing critical feedback on our tribute to Warren M. Zapol.

Conflicts of interest

None.

\section{Publisher's Note}

Springer Nature remains neutral with regard to jurisdictional claims in published maps and institutional affiliations.

Accepted: 7 January 2022

Published online: 21 January 2022 